
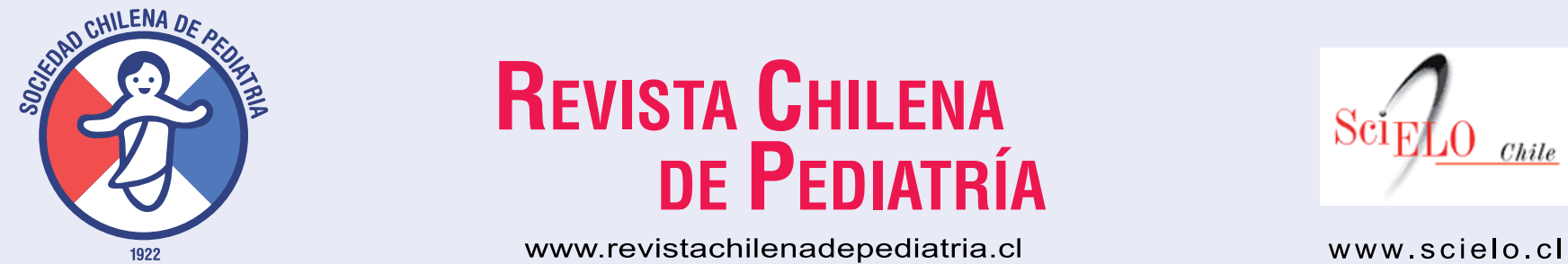

www.scielo.cl

Rev Chil Pediatr. 2017;88(4):562-563

DOI: 10.4067/S0370-410620170004000120

OBITUARIO

\section{Dr. Francisco Beas Franco}

Frente al reciente fallecimiento del Dr. Francisco Beas Franco, consideramos importante realizar una reseña de su vida y de sus obras dirigida a los pediatras que trabajaron de la mano con él y a aquéllos que siendo más jóvenes no lo conocieron.

El Profesor Francisco Beas Franco egresó de la Escuela de Medicina de la Universidad Católica de Chile, y se tituló en la Universidad de Chile en 1955. Comenzó a trabajar como ayudante en la Catedra del Profesor Julio Meneghello en el antiguo Hospital Arriarán manifestando especial interés en el estudio de los pacientes pediátricos con morbilidad endocrinológica y deseo de formar un Policlínico de esta especialidad.

En 1956 se constituyó ese Policlínico de Endocrinología Infantil pionero en Chile lo que desencadenó la necesidad de montar técnicas para determinaciones hormonales y la creación del Laboratorio de Endocrinología. Así el Doctor. Beas dió comienzo a la Especialidad de Endocrinología Infantil en Chile.

En los años 1960 -1962, realizó una beca de postgrado con el profesor Lytt Gardner considerado uno de los padres de la Endocrinología Infantil en la Universidad de Nueva York. En 1962 al retornar a Chile organizó la primera Unidad de Endocrinología y Genética del niño y del adolescente en el Hospital Arriarán.

Esta Unidad comenzó rápidamente a crecer abarcando ámbitos clínicos y de laboratorio de investigaciones pediátricas formándose numerosos jóvenes profesionales médicos, bioquímicos, químico farmacéuticos, tecnólogos, nutricionistas y enfermeras y se creó una unidad de hospitalización y de exploración funcional de pacientes endocrino- genéticos. A esto se sumó la creación de la Unidad de radioinmunoensayo para determinaciones hormonales más exactas y la implementación de un laboratorio de citogenética.

En 1973 siendo el Dr. Beas Director del departamento Materno Infantil de la Facultad de Medicina gestionó la unión del grupo pediátrico con un grupo obstétrico y se creó la Unidad de Reproducción Humana, dando origen al centro de investigaciones Materno Infantil.

El profesor Francisco Beas realizó numerosos trabajos, en lo que destacan el estudio de los mecanismos endocrinos y de adaptación en la desnutrición calórico-proteica, Kwashiorkor, el estudio de las patologías de crecimiento, desarrollo puberal y en el campo de la proteínas placentarias la descripción del factor uterotrofico placentario (UTPF) que tuvieron gran relevancia nacional e internacional

La mayoría de estas investigaciones se lograron a través de proyectos Fondecyt Universidad de Chile, National Institute of Health (NIH) Fundación Ford, Fundación Rockefeller, OMS, Unicef y otros. Estas investigaciones fueron publicadas en revistas y libros nacionales e internacionales.

La Universidad de Chile como justo reconocimiento a esta labor lo nombró Profesor Extraordinario de Pediatría en 1962 y Profesor Titular de Pediatría en 1971.

Perteneció, dirigió y co-fundó Sociedades científicas nacionales e internacionales como la Sociedad Latinoamericana de endocrinología pediátrica. Recibió el premio a la excelencia académica en el año 1998 otorgado por la Sociedad Chilena de Pediatría y nombrado miembro honorario de la sociedad de Endocrinología $y$ diabetes en el año 2011. Tuvo un reconocido prestigio nacional e internacional.

El Profesor Beas ocupó desde 1973 hasta 1992, la dirección del Centro de Investigaciones Materno Infantil y posteriormente del Instituto de Investigaciones Materno Infantil (IDIMI). Este último fue creado en 1989 permaneciendo por largos años como el único Centro formador de nuevos especialistas en Endocrinología pediátrica. Este Instituto logró conjugar las Ciencias básicas con la clínica conformando un polo de investigación pionero en la disciplina de Endocrinología pediátrica en Chile, donde se ha realizado docencia de pre y post grado no solo a médicos chilenos sino a becarios provenientes de diferentes países de toda Latinoamérica. Dejó la dirección de este Instituto a cargo del Dr. Fernando Cassorla quien después de haber sido Director del National Institute of Health vino a darle un nuevo impulso para que este Centro formador fuera lo que es hoy, no solo para Chile sino para numerosos especialistas de toda Latinoamérica.

Según muchos que trabajaron personalmente con el Dr. Beas, en el aspecto personal, se destacó no sólo por ser un muy buen clínico sino también un excelente investigador. Tenía una innata capacidad docente, 
perfeccionada con mucho estudio, la que entregó en forma generosa a todos aquellos alumnos o becarios que se le acercaron a solicitarle apoyo en un caso clínico o en investigación. Las puertas de su oficina siempre estuvieron abiertas para conversar con médicos, profesionales, técnicos, y personal de apoyo tratando de solucionar sus problemas. Fomentó el dialogo permanente aceptando a cada uno con distintas personalidades, intereses cualidades y defectos.

Fue un ejemplo de vida familiar, valorando como consecuencia también a las familias de quienes trabajaron con él.

También supo dejar tiempo para cultivar otros as- pectos del quehacer humano, lo social, lo religioso, las amistades, los viajes la lectura y el arte de la pintura, enriqueciendo su espíritu y permitiendo de esta forma desarrollar integralmente su vocación médica.

Con su partida, creemos interpretar a la mayoría de los endocrinólogos pediatras al expresar que dejó una huella imperecedera en nuestro ámbito de trabajo.

Dra. Cecilia Henríquez Endocrinóloga pediatra

Dra. M. Virginia Pérez F. Presidenta de Rama Endocrinología pediátrica 